\title{
NEUMONÍA BACTERIANA: ESCALA DIAGNÓSTICA
}

Bladimir Marín MD*, José Pineda MD**, Claudia Murcia MD***, Héctor Romero MD****, Jorge Carrillo $\mathrm{MD} * * * * *$.

\section{Resumen}

La neumonía es causa importante de morbimortalidad en la infancia. La diferenciación entre las bacterianas y las que no lo son puede generar dificultades para el clínico. La escala de Laura Moreno combina aspectos clínicos, radiológicos y de laboratorio con una sensibilidad del $100 \%$ y especificidad del 93.9\%, en el diagnóstico de neumonía bacteriana. Objetivo: describir la concordancia observada en el diagnóstico de neumonía bacteriana, al aplicar una escala de predicción aplicada por el pediatra y el radiólogo comparada con el diagnostico clínico, en los pacientes del servicio de pediatría del Hospital de San José. Metodología: se estudiaron niños con edades que variaron entre un mes y cinco años, hospitalizados con diagnóstico de neumonía en el periodo del $1^{\circ}$ de septiembre al 30 de noviembre de 2007. Se analizaron 73 pacientes que cumplieron los criterios de inclusión. Resultados: según el diagnóstico clínico 52 pacientes tenían NB, 18 neumonía viral y tres no fueron clasificados al ingreso. La frecuencia según sexo fue 31(42\%) para las niñas; el síntoma más frecuente fue la tos 72 (98\%); el hallazgo radiológico común fue el infiltrado bien definido $27(37 \%)$. El grado de concordancia entre radiólogo y pediatra fue bueno $(\mathrm{k}=0,77)$ y el observado entre la escala y el diagnóstico clínico fue bajo $(\mathbf{k}=\mathbf{0 , 1 9 )}$. Conclusiones: los datos encontrados al aplicar la escala de Laura Moreno crean el interrogante de si estamos sobrediagnosticando neumonías bacterianas, lo cual debe ser un estímulo para nuevos estudios en nuestra población.

Palabras clave: neumonía bacteriana, escala diagnóstica, escala radiológica. Abreviaturas: NB, neumonía bacteriana; NAC, neumonía adquirida en la comunidad.

\section{DIAGNOSTIC SCALE FOR BACTERIAL PNEUMONIA}

\section{Abstract}

Pneumonia is a major cause of morbidity and mortality in children. Clinicians often experience difficulty to distinguish between bacterial pneumonia (BP) and pneumonia caused by other agents. The Laura Moreno Scale combines clinical, radiological and laboratory aspects and shows a sensibility of $\mathbf{1 0 0 \%}$ and specificity of $\mathbf{9 3 . 9 \%}$ for the diagnosis of bacterial pneumonia. Objective: To describe the consistency rates for the diagnosis of bacterial pneumonia when the pediatrician and radiologist apply a predictor scale or use clinical criteria in patients admitted to the Pediatrics Service at the San José Hospital. Methodology: Children between the age of one month and five years admitted to the hospital

Fecha recibido: junio 9 de 2008 - Fecha aceptado: julio 30 de 2008

Residente III de pediatría, Fundación Universitaria de Ciencias de la Salud. Bogotá, D.C. Colombia.

** Residente II de pediatría Fundación Universitaria de Ciencias de la Salud. Bogotá D.C. Colombia.
*** Jefe del Servicio de Pediatría, Hospital de San José. Instructora Asistente, Fundación Universitaria de Ciencias de Salud. Bogotá D.C.Colombia.

***** Pediatra docente, Hospital San José, Bogotá D.C. Colombia.

*****Radiólogo docente, Hospital de San José, Bogotá D.C.Colombia. 
between September 1 and November 30, 2007 were included in the study. Seventy-three (73) patients who fulfilled the inclusion criteria were analyzed. Results: According to clinical diagnosis, 52 patients had BP, 18 had viral pneumonia and 3 were not classified upon admission. Gender-related frequency was $31(42 \%)$ for girls; cough $72(78 \%)$, was the most frequent symptom and the most common shared radiological finding was a well defined infiltrate in $27(37 \%)$ subjects. The consistency rate between the radiologist and pediatrician was $\operatorname{good}(k=0.77)$ and was low between the scale and clinical diagnosis $(k=0.19)$ Conclusions: Data obtained through the use of the Laura Moreno Scale raises the question: Are we over diagnosing bacterial pneumonias? This must encourage additional studies to be conducted in our population.

\section{Key words: bacterial pneumonia, diagnostic scale, radiological scale}

\section{Introducción}

En Colombia los menores de cinco años con sospecha de neumonía entre 1999 y 2005 fue $10 \%$ de la población y de ellos el $57 \%$ fueron conducidos a un centro de atención en salud. ${ }^{1,2,3}$ En el 2005 se presentaron 139 fallecimientos por esta causa en niños y niñas con residencia habitual en Bogotá, que equivale a una tasa de 20,7 por 100.000 menores de cinco años. Durante 2006 se presentaron 133 casos de mortalidad por enfermedad respiratoria aguda de niños y niñas en Bogotá. De los anteriores, 97 correspondieron a neumonía $(72,9 \%)$. La tasa de mortalidad por esta afección para el año 2006 fue de $13,9 \times 100.000$. La estadística del Hospital de San José (HSJ) en el año 2006, reportó 537 pacientes hospitalizados con diagnóstico de neumonía y hasta junio de 2007 se registraron 218 pacientes en toda la población pediátrica. ${ }^{4,5,6,7}$

Los virus son responsables del $45 \%$ de NAC en el grupo de edad pediátrica y son muy comunes en los niños de tres semanas a cuatro años de edad. 8,9,10,11 Sin embargo, los reportes de la literatura son limitados. Los aislados con mayor frecuencia son el sincicial respiratorio, el parainfluenza, el influenza A y B y los adenovirus. La epidemiología de la NAC bacteriana difiere según la edad y se ha visto influida por las estrategias vacunales. Desde el nacimiento hasta las tres semanas de edad, la causa más común es el Streptococcus B y los bacilos gram negativos. La neumonía afebril en esta edad está causada a menudo por Chlamydia trachomatis. El Streptococcus pneumoniae es la causa más importante de neumonía febril en niños de tres semanas a cuatro años de edad. Otras bacterias aisladas con menor frecuencia incluyen Haemophilus influenzae, Streptococcus pyogenes, Staphylococcus aureus y otras especies de estreptococos. En los niños mayores de cinco años los patógenos bacterianos usuales son Mycoplasma pneumoniae y Chlamydophila pneumoniae. 1,2,9,11

Es difícil definir qué proporción de las infecciones de las vías respiratorias bajas es bacteriana, debido a las dificultades técnicas del diagnóstico (obtención de cultivos, serotipificación viral, costos, poca disponibilidad y la baja sensibilidad demostrada con el hemocultivo) y a que muchos pacientes han recibido antibióticos antes de llegar al hospital. Como lo raro es contar con el diagnóstico etiológico en forma oportuna, la decisión terapéutica inicial suele basarse en elementos clínicos, de laboratorio y radiológicos sin un consenso general. ${ }^{12,13,14,15}$

La placa de tórax es la técnica imagenológica más utilizada para aproximarse al diagnóstico de neumonía por su bajo costo, disponibilidad y la posibilidad de observar diferentes patrones que facilitan el acercamiento al agente etiológico viral o bacteriano. ${ }^{16,17,18,19,20,21}$ Hace parte de algunas escalas de diagnóstico de NB como las de Khamapirad y Glezen $^{22}$ y Laura Moreno ${ }^{23}$ que incluyen criterios clínicos, paraclínicos y radiológicos. Han demostrado tener una adecuada sensibilidad y especificidad (84 y 100; 89\% y 93.8\% respectivamente). Son útiles para lograr un buen enfoque en el diagnóstico de infección bacteriana o no en la población pediátrica. Con el presente estudio se buscan estrategias que 
favorezcan el diagnóstico de NB con el propósito de facilitar un uso racional de antibióticos, reducir la resistencia bacteriana, racionalizar la utilización de recursos y disminuir costos.

\section{Métodos}

El estudio fue aprobado por el comité de investigaciones de la facultad de medicina de la Fundación Universitaria de Ciencias de la Salud. No requirió consentimiento informado. Previo al inicio de la recolección de datos se obtuvo respuesta de la Dra. Laura Moreno autorizando la aplicación de la escala. El objetivo es analizar el diagnostico de NB, al utilizar una escala de predicción ${ }^{23}$ (Tabla 1) aplicada por un pediatra y un radiólogo, comparada con el diagnóstico clínico en niños de un mes a cinco años, hospitalizados en el servicio de pediatría del Hospital de San José, con diagnóstico de neumonía, en el período de septiembre $1^{\circ}$ a noviembre 30 de 2007 . La muestra estuvo conformada por casos consecutivos excluyendo pacientes admitidos en la unidad de cuidado intensivo pediátrico, aquellos con antecedentes de cardiopatía congénita, enfermedad pulmonar crónica, neumonía recurrente, desnutrición crónica, neumonía nosocomial, displasia broncopulmonar y neumonía atípica.

Los pacientes fueron valorados por el pediatra de turno quien definió el diagnóstico de ingreso (neumonía bacteria o viral) de acuerdo con su criterio clínico sin conocimiento de la escala. Dentro de las siguientes 24 horas dos evaluadores (pediatra y radiólogo) realizaron la lectura de la radiografía de tórax de

\begin{tabular}{|c|c|}
\hline PREDICTORES & PUNTOS: \\
\hline $\begin{array}{l}\text { Temperatura axilar }>0=39^{\circ} \mathrm{C} \\
\text { Edad }>0=9 \text { meses } \\
\text { Conteo neutrófilos absolutos }>0=8.000 \\
\text { Bandas }>0=5 \%\end{array}$ & $\begin{array}{l}3 \\
2 \\
2 \\
1\end{array}$ \\
\hline \multicolumn{2}{|c|}{ RADIOGRAFÍA DETÓRAX } \\
\hline Infiltrados & $\begin{array}{l}\text { I: Bien definidos }=2 \text { puntos } \\
\text { 2: Pobremente definidos = I punto } \\
\text { 3: Intersticiales = -I punto }\end{array}$ \\
\hline Localización & $\begin{array}{l}\text { I: Un solo lóbulo = I punto } \\
\text { 2. Múltiples lóbulos en uno o ambos pulmones bien definidos = } \\
\text { I punto } \\
\text { 3. Múltiples sitios pobremente definidos = I punto }\end{array}$ \\
\hline Fluido espacio pleural & $\begin{array}{l}\text { I.Borramiento mínimo de senos }=1 \text { punto } \\
\text { 2. Derrame evidente }=2 \text { puntos }\end{array}$ \\
\hline Absceso, bula o neumatocele & $\begin{array}{l}1 . \text { Dudoso }=1 \text { punto } \\
2 \text { Evidente }=2 \text { puntos }\end{array}$ \\
\hline Atelectasia & $\begin{array}{l}\text { I. Subsegmentaria }=-I \text { punto } \\
2 \text { Lobar medio y lóbulo superior }=I \text { punto } \\
\text { 3. Lobar otros lóbulos }=0 \text { puntos }\end{array}$ \\
\hline
\end{tabular}

*Escala neumonía bacteriana Laura Moreno.23 


\section{Características}

\section{Tabla 2. Características demográficas y clínicas}

Neumonía

bacteriana

Neumonía viral

Neumonía no

especificada

Total

n (\%)

\begin{tabular}{|c|c|c|c|c|}
\hline & $52(71,2)$ & $18(24,6)$ & $3(4, I)$ & $73(100)$ \\
\hline Edad (meses): promedio DS & $18,9(17)$ & $21(21,9)$ & $23(23,2)$ & $19,6(18)$ \\
\hline mediana & 14,5 & 14 & 19 & 15 \\
\hline & & - & & \\
\hline Sexo femenino & $24(46)$ & $5,27,7)$ & $2(66,6)$ & $31(42,4)$ \\
\hline Sexo masculino & $28(90)$ & $2(6)$ & $\mathrm{I}(3,2)$ & $42(58)$ \\
\hline \multicolumn{5}{|l|}{ Estrato socioeconómico } \\
\hline 2 & $38(73)$ & $11(6 I)$ & $3(100)$ & $51(69,8)$ \\
\hline 3 & $10(19)$ & $5(27,7)$ & - & $15(20,5)$ \\
\hline 4 & $2(3,8)$ & - & - & $2(2,7)$ \\
\hline 6 & $2(3,8)$ & $2(11)$ & - & $4(5,4)$ \\
\hline \multicolumn{5}{|l|}{ Síntomas respiratorios } \\
\hline Tos & $51(98)$ & $18(100)$ & $3(100)$ & $72(98,6)$ \\
\hline Tirajes & $1 \mathrm{II}(2 \mathrm{I})$ & $7(38,8)$ & & $18(24,6)$ \\
\hline Cianosis & $15(28,8)$ & $7(38,8)$ & $2(66,6)$ & $24(32,8)$ \\
\hline Aleteo nasal & $I(I, 9)$ & - & - & $\mathrm{I}(\mathrm{I}, 3)$ \\
\hline Antibiótico previo & $2(3,8)$ & $5(27,7)$ & - & $7(9,5)$ \\
\hline Temperatura axilar $\geq 39^{\circ} \mathrm{C}$ & $4(7,7)$ & $2(11)$ & - & $6(8,2)$ \\
\hline Conteo neutrófilos absoluto: $\geq 8.000$ & $33(63,5)$ & $7(38,8)$ & $\mathrm{I}(33)$ & $41(56)$ \\
\hline bandas $\geq 5 \%$ & $16(30,8)$ & $3(16,6)$ & - & $19(26)$ \\
\hline \multicolumn{5}{|l|}{ Lectura radiografía pediatra } \\
\hline \multicolumn{5}{|l|}{ Tipo infiltrados } \\
\hline Bien definido & $2 I(6 I, 7)$ & $5(27,7)$ & $\mathrm{I}(33)$ & $27(37)$ \\
\hline Pobre definido & $12(35)$ & $5(27,7)$ & & $17(23)$ \\
\hline Intersticial & $\mathrm{I}(2,9)$ & $7(38,8)$ & $2(\overline{66}, 6)$ & $10(13,6)$ \\
\hline \multicolumn{5}{|l|}{ Localización } \\
\hline Un solo lóbulo & $26(76)$ & $7(38,8)$ & $I(66,6)$ & $34(46,5)$ \\
\hline Múltiples bien definidos & $7(20,5)$ & $2(11)$ & - & $10(13,6)$ \\
\hline Múltiples mal definidos & $\mathrm{I}(2,9)$ & $3(28)$ & - & $4(5,4)$ \\
\hline \multicolumn{5}{|l|}{ Derrame } \\
\hline Evidente & $2(5,8)$ & - & - & $2(2,7)$ \\
\hline No evidente & - & - & - & - \\
\hline \multicolumn{5}{|l|}{ Absceso } \\
\hline Evidente & - & - & - & - \\
\hline Dudoso & - & - & - & - \\
\hline \multicolumn{5}{|l|}{ Neumatocele } \\
\hline Evidente & - & - & - & - \\
\hline Dudoso & - & - & - & - \\
\hline \multicolumn{5}{|l|}{ Bula } \\
\hline Evidente & - & - & $\begin{array}{cc}- \\
-\end{array}$ & - \\
\hline Dudoso & - & - & - & - \\
\hline \multicolumn{5}{|l|}{ Atelectasia } \\
\hline Subsegmentaria & $\mathrm{I}(2,9)$ & - & - & $I(I, 3)$ \\
\hline Lóbulos medio y superior & $2(5,8)$ & - & - & $2(2,7)$ \\
\hline Otros lóbulos & $2(5,8)$ & - & - & $2(2,7)$ \\
\hline
\end{tabular}


Tabla 3. Características demográficas y clínicas evaluadas por pediatra

Neumonía bacteriana

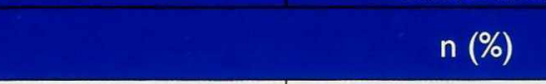

Edad (meses): promedio DS

mediana

Sexo femenino

Sexo masculino

Estrato socioeconómico

2

3

4

6

Síntomas respiratorios

Tos

Tirajes

Cianosis

Aleteo nasal

Uso previo de antibiótico

Temperatura axilar $\geq 39^{\circ} \mathrm{C}$

Temperatura promedio

Conteo neutrófilos absoluto $\geq 8.000$

Conteo neutrófilos promedio

Bandas $\geq 5 \%$

Lectura radiografía pediatra

Tipo infiltrados

\begin{tabular}{|c|c|c|c|}
\hline Bien definido & $21(61,7)$ & $3(7,6)$ & $24(32,8)$ \\
\hline Pobre definido & $12(35)$ & $13(33)$ & $25(34,2)$ \\
\hline Intersticial & $I(3)$ & $21(53,8)$ & $22(30)$ \\
\hline \multicolumn{4}{|l|}{ Localización } \\
\hline Un solo lóbulo & $26(76)$ & $6(15)$ & $32(43,8)$ \\
\hline Múltiples bien definidos & $7(20,5)$ & $4(10)$ & $11(15)$ \\
\hline Múltiples mal definidos & $I(3)$ & II (28) & $12(16,4)$ \\
\hline \multicolumn{4}{|l|}{ Derrame } \\
\hline Evidente & $2(5,8)$ & - & $2(2,7)$ \\
\hline No evidente & - & - & - \\
\hline Absceso-neumatocele y bula & - & - & - \\
\hline \multicolumn{4}{|l|}{ Atelectasia } \\
\hline Subsegmentaria & $I(3)$ & - & $\mathrm{I}(\mathrm{I}, 4)$ \\
\hline Lóbulo medio y superior & - & - & \\
\hline Otros lóbulos & $2(5,8)$ & - & $2(2,7)$ \\
\hline
\end{tabular}

Neumonía No

bacteriana

Total

n (\%)

$34(46,5)$

$28,5(16,9)$

23,5

20(59)

14(33)

26(76)

$7(20.5)$

$\mathrm{I}(3)$

0

$39(53,5)$

$11,8(15,8)$

3

II(28)

28(77)

$26(66,6)$

$8(20,5)$

$\mathrm{I}(2,5)$

$4(10)$

$73(100)$

$19,6(18)$

15

$3 \mid(42)$

42(64)

$52(71)$

$15(20,5)$

$2(2,7)$

$4(5,4)$

$33(45.8)$

$7(9,7)$

I I $(15,2)$

0

39(54)

II $(15,2)$

46(63)

13(18)

I $(2,5)$

$18(25)$

24(33)

I(I)

$2(5,8)$

$5(12,8)$

$7(9,5)$

$6(8,2)$

$6(17,6)$

0

37,1

$37,4(1,02)$

26(76)

$36,8(0,72)$

$4 \mathrm{I}(56)$

12885

15(38)

6675

9602

13(38)

$6(15)$

19(26)

$13(38)$
-2

$6(15)$

$2(2,7)$ 
manera independiente. Después de este proceso los investigadores aplicaron la escala con los criterios clínicos, de laboratorio y lectura radiográfica por los dos evaluadores, obteniendo un puntaje global. No se modificó ninguna conducta establecida por el servicio de pediatría durante el desarrollo del estudio. Las variables para análisis se obtuvieron de la historia clínica de ingreso: edad, sexo, síntomas respiratorios (tos, tirajes, cianosis, aleteo nasal), frecuencia respiratoria, previo uso de antibióticos, temperatura, cuadro hemático (neutrófilos absolutos y bandas), hallazgos radiológicos y diagnóstico clínico. Se evaluó el grado de concordancia entre la escala y el diagnóstico clínico del pediatra de turno, el acuerdo interobservador de la lectura radiológica (pediatra-radiólogo) y la concordancia entre el diagnóstico clínico, la escala del pediatra y del radiólogo, calculando el índice kappa. Las puntuaciones mayores de 4 se asocian con neumonía bacteriana con una sensibilidad de $100 \%$, especificidad $93.8 \%$, valor predictivo positivo del $75.8 \%$ y valor predictivo negativo $100 \%$.

Análisis estadístico: se utilizó el software SPSS 12,0 ( ). Las variables continuas se definen como media y desviación estándar. Se describe la mediana cuando no se cumple el supuesto de distribución normal o cuando existen datos extremos. Las variables categóricas se anotan como porcentajes. El acuerdo observado se expresa en frecuencias absolutas y relativas y la concordancia se reporta como índice kappa. Un valor kappa entre 0 y 0,20 se considera muy bajo, de 0,21 a 0,40 bajo, entre 0,41 y 0,60 moderado acuerdo, entre 0,61 y 0,80 bueno y de 0,8 a 1,0 excelente.

\section{Resultados}

Entre septiembre $1^{\circ}$ y noviembre 30 de 2007 del total de pacientes admitidos con diagnóstico de neumonía en el servicio de pediatría del Hospital de San José, 73 cumplieron los criterios de inclusión para el estudio: $52(71 \%)$ diagnosticados por el pediatra de turno como NB, $18(24,6 \%)$ como neumonía viral y tres con neumonía no especificada. La Tabla 2 muestra las características demográficas y clínicas

\begin{tabular}{|c|c|}
\hline \multicolumn{2}{|c|}{ Tabla 4. Neumonía con taquipnea } \\
\hline Frecuencia respiratoria & $\begin{array}{c}\text { Pacientes con taquipnea } \\
n(\%)\end{array}$ \\
\hline Menor de 2 meses \\
$\geq 60$ \\
$n=15$
\end{tabular}

\begin{tabular}{|l|c|c|}
\hline \multicolumn{2}{|c|}{ Tabla 5. Correspondencia e índice Kappa } \\
\hline \multicolumn{1}{|c|}{ Evaluador } & $\begin{array}{c}\text { Porcentaje } \\
\text { de acuerdo }\end{array}$ & $\begin{array}{c}\text { Índice } \\
\text { kappa }\end{array}$ \\
\hline $\begin{array}{l}\text { Diagnóstico pediatra } \\
\text { de turno (ingreso) vs. } \\
\text { pediatra que aplica escala }\end{array}$ & $58 \%$ & 0,21 \\
\hline $\begin{array}{l}\text { Diagnóstico pediatra } \\
\text { de turno (ingreso) vs. } \\
\text { radiólogo que aplica } \\
\text { escala }\end{array}$ & $55 \%$ & 0,17 \\
\hline $\begin{array}{l}\text { Diagnóstico pediatra que } \\
\text { aplica escala vs. radiólogo } \\
\text { que aplica escala }\end{array}$ & $89 \%$ & 0,78 \\
\hline $\begin{array}{l}\text { Diagnóstico pediatra } \\
\text { de turno (ingreso) vs. } \\
\text { pediatra que aplica escala } \\
\text { vs. radiólogo que aplica } \\
\text { escala }\end{array}$ & $51,5 \%$ & 0,34 \\
\hline
\end{tabular}

de la población del estudio. La distribución por sexo fue de $31(42 \%)$ niñas y $42(58 \%)$ niños. El promedio de edad fue 19,6 meses; la edad mediana 15 meses con un rango entre uno y 60 meses. El $69 \%$ de los pacientes pertenecían a nivel socio económico estrato 2 por clasificación del SISBEN. El síntoma respiratorio más frecuente fue la tos 72 (98\%); el elemento paraclínico utilizado fue el conteo de neutrófilos 41(56\%). El mayor hallazgo radiológico fue infiltrado bien definido $27(37 \%)$ y en un solo lóbulo 34 (46,5\%). 
La Tabla 3 muestra las características demográficas y clínicas de la población del estudio aplicando la escala. La frecuencia de NB es $34(46,5 \%)$ y no bacteriana $39(53,5 \%)$. El hallazgo radiológico más común fue infiltrado pobremente definido 25 (34\%) y en un solo lóbulo $32(43,8 \%)$. Los pacientes que ingresaron con taquipnea fueron $31(42,4 \%)$; cinco menores de dos meses de edad, ocho entre dos y doce meses y 18 mayores de doce meses (Tabla 4). La correspondencia observada y los índices kappa se presentan en la Tabla 5.

La correspondencia entre radiólogo y pediatra para los hallazgos radiológicos se presentan en las Figuras $1,2,3$ y 4 . La presencia de abscesos, neumatocele y bulas fue de $0 \%$, tanto para el radiólogo como para el pediatra.

\section{Discusión y conclusiones}

El propósito del estudio fue determinar la concordancia entre el diagnóstico de neumonía al utilizar una escala de predicción de NB aplicada por un pediatra y un radiólogo, comparados con el diagnóstico clínico del Hospital de San José mediante el índice kappa. Esta fue buena entre el radiólogo y el pediatra al aplicar la escala, lo que significa que la precisión es fiable debido a la interpretación sencilla del instrumento que reduce al mínimo la discrepancia y asegura la unidad de criterios. La concordancia coincide con datos de los autores del modelo seleccionado (Laura Moreno ${ }^{23}$ ), sin embargo encontramos un bajo nivel de correspondencia entre el diagnóstico clínico y la aplicación de la escala por los dos evaluadores. Si bien el diagnóstico podría estar apoyado en otros criterios no evaluados en el instrumento (estertores, aspecto tóxico, tiempo de evolución, dificultad respiratoria, esquema de vacunación), no explica por qué en nuestro servicio se diagnostican más NB que lo reportado en la literatura donde se observa para la mayoría de NAC entre un mes y cuatro años de edad son de etiología viral. ${ }^{1,24,25}$ Tal vez no le damos la importancia a parámetros clínicos como la taquipnea y la presencia de fiebre alta ( temperatura mayor de $39^{\circ} \mathrm{C}$ ) los cuales han

\section{Tipo de Infiltrados}

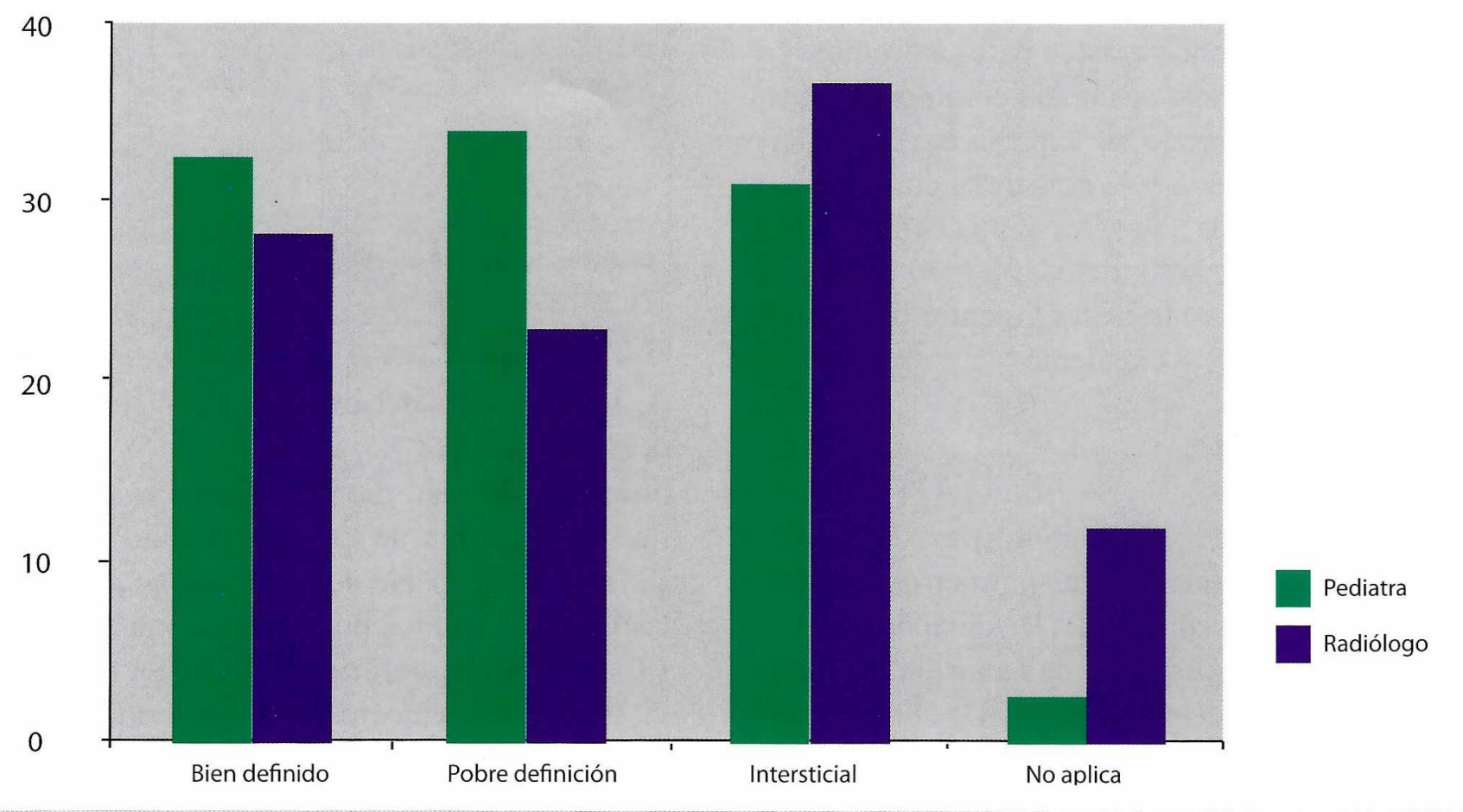

Figura I. Hallazgos radiológicos y tipo de infiltrado. 


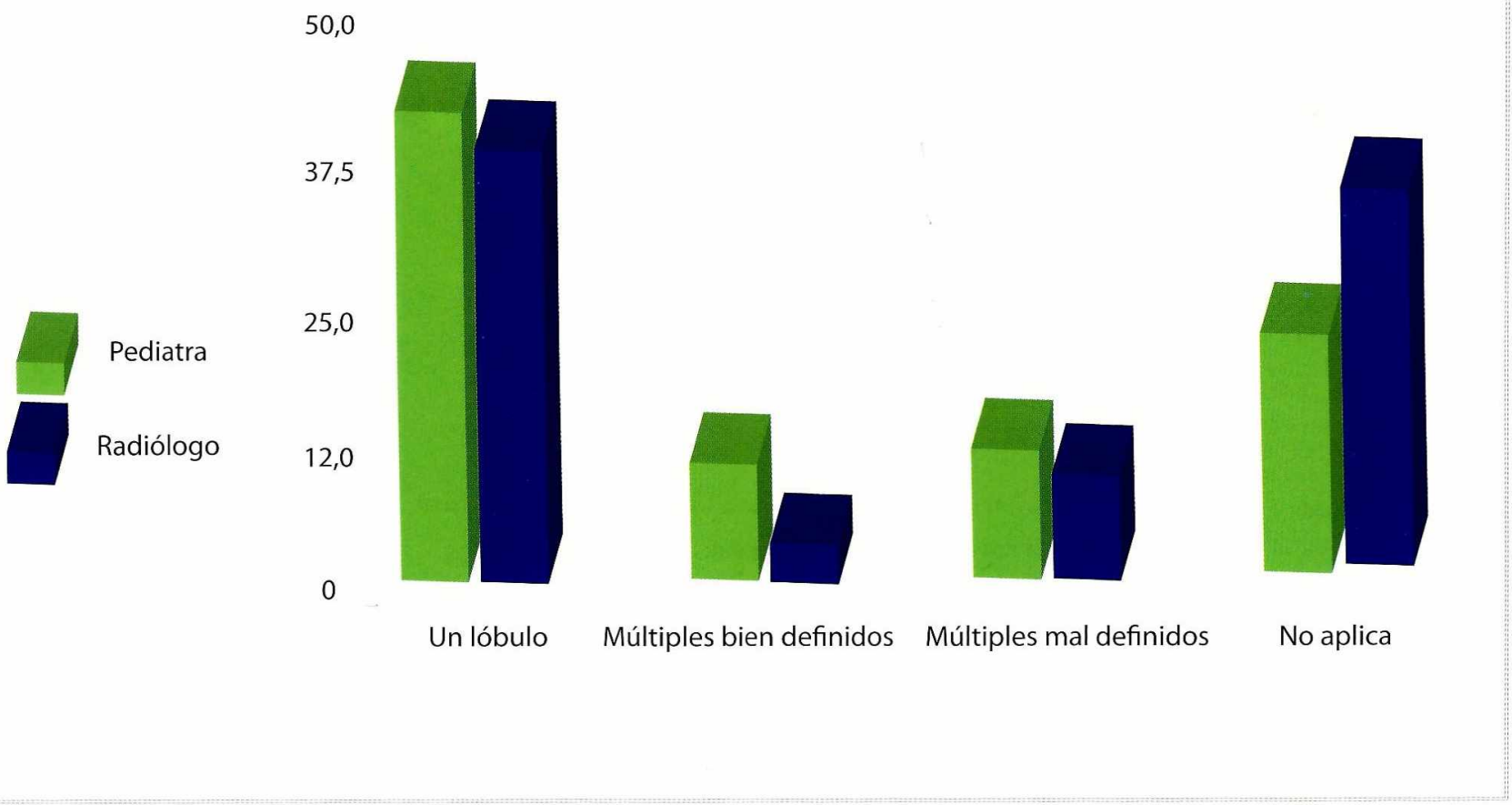

Figura 2. Hallazgos radiológicos y localización de infiltrados.

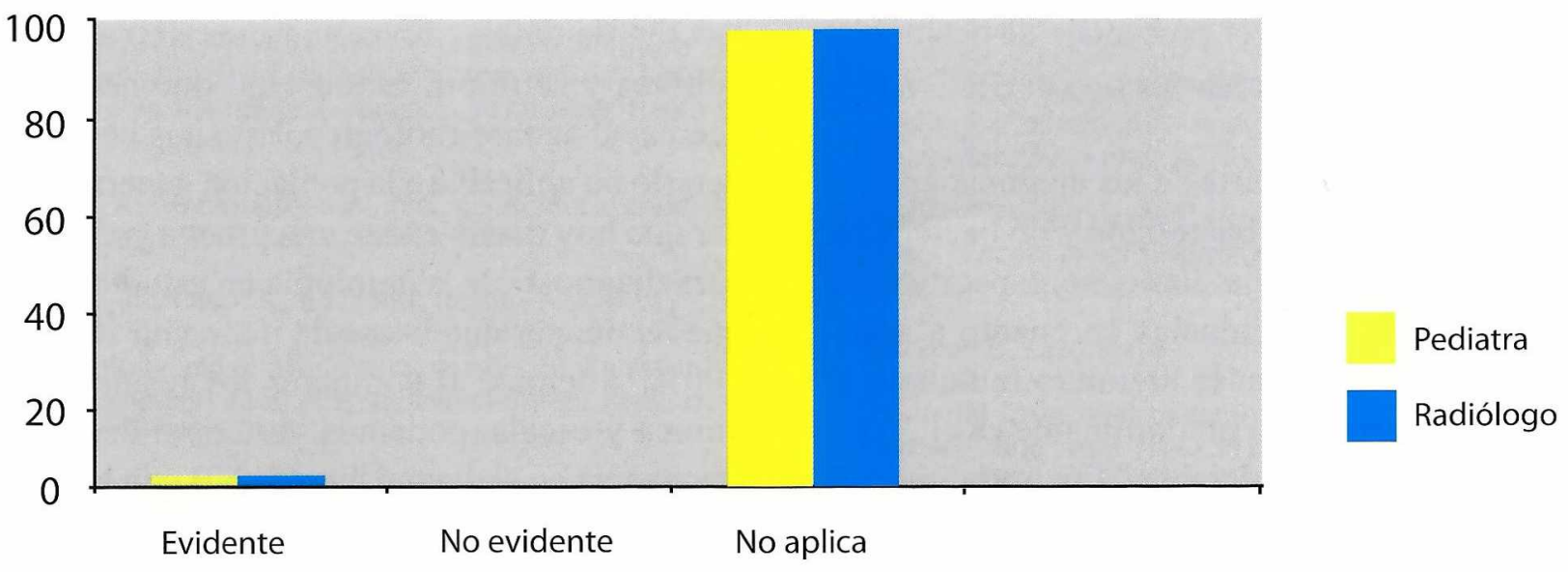

Derrame pleural

Figura 3. Hallazgos radiológicos: derrame pleural.

demostrado ser indicadores muy sensibles de infección bacteriana ${ }^{12} \mathrm{y}$ otros paraclinicos como el conteo anormal de neutrófilos y la presencia de bandas. ${ }^{18}$ Es de tener en cuenta que la radiografía de tórax además de ayudarnos en la localización topográfica y la magnitud de la lesión, precisa la etiología ${ }^{12,19,20}$ como lo confirman las alteraciones radiológicas identificadas por los evaluadores que fueron muy similares cuando 


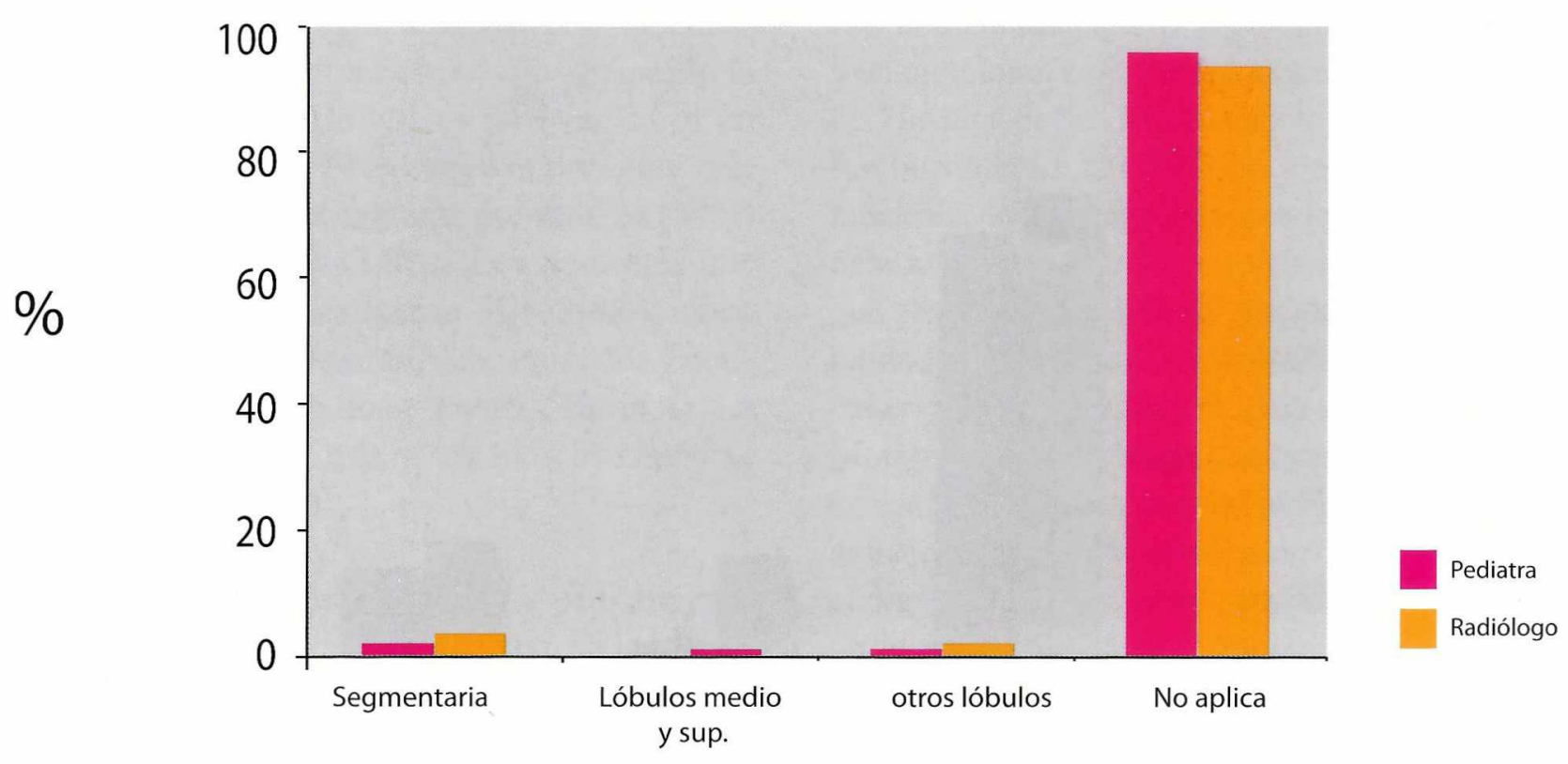

Atelectasias

Figura 4. Hallazgos radiológicos: atelectasias.

los hallazgos son claros y bien definidos; se destaca que en la muestra el mayor porcentaje de neumonías corresponde a las no complicadas.

Observamos que gran parte de los diagnósticos clínicos se clasificaron en bacteriana y no bacteriana, y un pequeño porcentaje como no especifico; la muestra no mostró diferencias en cuanto a género, lo cual es acorde con la literatura mundial'; el estrato socio económico predominante es el 2, que es la población más vulnerable. ${ }^{9}$ Encontramos que los síntomas respiratorios en orden de frecuencia son: tos, cianosis, tirajes y aleteo nasal, el cual es poco descrito posiblemente por que no se pregunta, no se busca o no se anota en las historias clínicas. Todos son signos y síntomas clásicos de la neumonía. ${ }^{12,13,14,25,26}$ Pareciera que nuestros pacientes no usaran antibiótico previo a la consulta médica, en vista de que se detectaron pocos casos de consumo.

Es de anotar que nuestro estudio tiene limitaciones dado el tamaño de la muestra, la realización en un solo centro hospitalario, el período corto de recolección de datos y no contar con elementos como cultivos y serotipificación viral que nos pudieran acercar al agente etiológico. Esto nos lleva a considerarlo no aplicable a la población general, sin olvidar que hoy día no existe una prueba gold estándar para diagnosticar la patología en estudio; pero hay que reconocer que la escala tiene una sensibilidad $100 \%$. Además, al comparar los resultados entre clínica y escala, podemos ver como disminuye la frecuencia en el diagnóstico de NB con la escala, lo que hace pensar que la probabilidad de aplicar esta prueba para detectar verdaderos enfermos de NB puede ser apropiado. El presente estudio pretende ser el punto de partida para crear nuevas líneas de investigación en el área de enfermedades respiratorias en nuestro servicio de pediatría. Se recomienda para investigaciones posteriores utilizar un tiempo de recolección y una población más amplias, ver la posibilidad de mejorar la detección de agentes etiológicos con cultivos, serotipificación viral, pruebas de inmunofluorescencia, procalcitonina y reacción en cadena polimerasa. Además estimular 
a docentes y estudiantes para continuar con este trabajo en pro del fortalecimiento del diagnóstico de la patología respiratoria y en beneficio de la población infantil.

\section{Referencilas}

1. Sandora TJ, Harper MB. Pneumonia in hospitalized children. Pediatr Clin North Am. 2005 Aug; 52(4):1059-81.

2. UNICEF. Declaración conjunta de la OMS y el UNICEF sobre el tratamiento de la neumonía en el medio comunitario. New York: UNICEF; 2004.

3. Alvis Guzmán N, de la Hoz Restrepo F, Higuera AB, Pastor D, Di Fabio JL. [The economic costs of pneumonia in children under 2 years of age in Colombia]. Rev Panam Salud Publica. 2005 Mar; 17(3):178-83. Spanish.

4. Bogotá (Colombia). Secretaria Distrital de Salud. Estadisticas julio-diciembre del 2005. SDS Boletín. 2005; 5.

5. Hospital de San José. Estadística de neumonía en pediatría ener-jul. 2007. Bogota: HSJ. Departamento de Estadística; 2007.

6. Rudan I, Tomaskovic L, Boschi-Pinto C, Campbell H. WHO child health epidemiology reference group global estimate of the incidence of clinical pneumonia among children under five years of age. Bull World Health Organ. 2004 Dec; 82(12):895-903.

7. OMS, UNICEF, UNDP. Reunión consultiva internacional sobre el control de las infecciones respiratorias agudas. Neumonía en los niños: estrategias para hacer frente al desafío. Washington DC : OMS; 1991.

8. McIntosh K. Community-acquired pneumonia in children. N Engl J Med. 2002 Feb 7; 346(6):429-37.

9. Michelow IC, Olsen K, Lozano J, Rollins NK, Duffy LB, Ziegler T, Kauppila J, Leinonen M, McCracken GH Jr. Epidemiology and clinical characteristics of communityacquired pneumonia in hospitalized children. Pediatrics. 2004 Apr; 113(4):701-7.

10. Cardeñosa Cendrero JA, Solé-Violán J, Bordes Benítez A, Noguera Catalán J, Arroyo Fernández J, Saavedra Santana P, Rodríguez de Castro F. Role of different routes of tracheal colonization in the development of pneumonia in patients receiving mechanical ventilation. Chest. 1999 Aug; 116(2):462-70.

11. Wijnands GJ. Diagnosis and interventions in lower respiratory tract infections. Am J Med. 1992 Apr 6; 92(4A): 91S-97S.

12. Palafox $M$, Guiscafré $H$, Reyes $H$, Munoz $\mathrm{O}$, Martínez
H. Diagnostic value of tachypnoea in pneumonia defined radiologically. Arch Dis Child. 2000 Jan; 82(1):41-5.

13. OMS-OPS. AIEPI: La atención integrada a las enfermedades prevalentes de la infancia en manos de la comunidad. Washington: OPS; 2003.

14. Mulholland EK, Simoes EA, Costales MO, McGrath EJ, Manalac EM, Gove S. Standardized diagnosis of pneumonia in developing countries. Pediatr Infect Dis J. 1992 Feb; 11(2):77-81.

15. Bachur R, Perry H, Harper MB. Occult pneumonias: empiric chest radiographs in febrile children with leukocytosis. Ann Emerg Med. 1999 Feb; 33(2):166-73.

16. Toikka P, Virkki R, Mertsola J, Ashorn P, Eskola J, Ruuskanen $O$. Bacteremic pneumococcal pneumonia in children. Clin Infect Dis. 1999 Sep; 29(3):568-72.

17. Lynch T, Platt R, Gouin S, Larson C, Patenaude Y. Can we predict which children with clinically suspected pneumonia will have the presence of focal infiltrates on chest radiographs? Pediatrics. 2004 Mar; 113(3 Pt 1):e186-9.

18. Campbell SG, Marrie TJ, Anstey R, Dickinson G, AckroydStolarz S. The contribution of blood cultures to the clinical management of adult patients admitted to the hospital with community-acquired pneumonia: a prospective observational study. Chest. 2003 Apr; 123(4):1142-50.

19. Katz DS, Leung AN. Radiology of pneumonia. Clin Chest Med. 1999 Sep; 20(3):549-62.

20. Gharib AM, Stern EJ. Radiology of pneumonia. Med Clin North Am. 2001 Nov; 85(6):1461-91.

21. Tarver RD, Teague SD, Heitkamp DE, Conces DJ Jr. Radiology of community-acquired pneumonia. Radiol Clin North Am. 2005 may; 43(3):497-512.

22. Khamapirad T, Glezen P. Clinical and radiographic assessment of acute lower respiratory tract disease in infants and children. Sem Respir Infect. 1987; 2(2):130-44.

23. Moreno L, Krishnan JA, Duran P, Ferrero F. Development and validation of a clinical prediction rule to distinguish bacterial from viral pneumonia in children. Pediatr Pulmonol. 2006 Apr; 41(4):331-7. Erratum in: Pediatr Pulmonol. 2006 May; 41(5):494.

24. Bartlett JG, Dowell SF, Mandell LA, File Jr TM, Musher DM, Fine MJ. Practice guidelines for the management of community-acquired pneumonia in adults. Infectious Diseases Society of America. Clin Infect Dis. 2000 Aug; 31(2):347-82.

25. Berman S. Acute respiratory infections. Infect Dis Clin North Am. 1991 Jun; 5(2):319-36.

26. Gaston B. Pneumonia. Pediatr Rev. 2002 Apr; 23(4):13240. 